\title{
GLITEROS enteral formula based on tempeh flour and jicama flour for patients with hyperglycemia
}

\author{
Sutikno, V., Rahadiyanti, A., Fitranti, D.Y., Dieny, F.F., Afifah, D.N. and *Nissa, C. \\ Department of Nutrition Science, Faculty of Medicine, Diponegoro University, Semarang, Indonesia
}

\author{
Article history: \\ Received: 29 December 2019 \\ Received in revised form: 1 \\ March 2020 \\ Accepted: 3 April 2020 \\ Available Online: 30 May \\ 2020
}

\section{Keywords:}

Hyperglycemia,

Enteral formula,

Tempeh flour,

Jicama flour

\section{DOI:}

https://doi.org/10.26656/fr.2017.4(S3).S17

\begin{abstract}
Critically ill patients are susceptible to hyperglycemia during the treatment in the hospital. This condition could reduce immunity and increase the risk of mortality. The use of commercial diabetes-specific enteral reduces blood glucose level but increase the hospitalization cost due to the long-term period. Therefore, the homemade enteral formula developed using tempeh flour and jicama flour. GLITEROS comes from glycemia, tempeh and Pachyrhizus erosus. Arginine, glycine, and isoflavone contained in tempeh flour could improve insulin secretion. Moreover, inulin in jicama flour could control the increasing of blood glucose levels. The purpose of this study was to analyze the viscosity, macro-nutrient content, food fiber and protein digestibility of GLITEROS enteral formula. GLITEROS made from tempeh flour, jicama flour, soybean oil, skim milk, maltodextrin, and sugar. This study was an experimental design with three groups formula, A1 (1:1), A2 (5:3), A3 (2:3). Variables include viscosity, energy density, energy content, carbohydrates, protein, fat, dietary fiber and protein digestibility each with $3 \mathrm{x}$ repetitions in duplicate. The data were analyzed using Kruskal Wallis and One-way ANOVA. A1 formula had the highest carbohydrate (62\%), dietary fiber (25.59\%), and fat (10.49\%) lower than A2 and A3 formula. A2 formula had $0.98 \mathrm{kcal} / \mathrm{mL}$ density energy and $984 \mathrm{kcal}$ energy, $11,73 \mathrm{cP}$ lower than A3 and A1 formula. A3 formula had the highest density energy $(1.13 \mathrm{kcal} /$ $\mathrm{mL}$ ), energy (1132.45 kcal), $36.10 \mathrm{cP}$ viscosity, and protein (14.89\%) lower than A1 and A2 formula. A1 formula is the most eligible in viscosity, energy density, energy content and protein of enteral formula for hyperglycemia patient according to American Diabetes Association (ADA), Canadian Diabetes Association (CDA), American Society of Parenteral and Enteral Nutrition (ASPEN) requirements.
\end{abstract}

\section{Introduction}

Hyperglycemia is a common complication in critically ill patients with a mortality rate $31 \%$ higher than patients with diabetes and normoglycaemia (Godinjak et al., 2015). The increase in blood glucose levels in critical patients due to the release of counter regulatory hormones causes a decrease in insulin production, disrupts the glucose utilization by peripheral tissues and enhance the process of gluconeogenesis in the liver (Gosmanov and Umpierrez, 2013; Godinjak et al., 2015). Glycemic control and good nutritional support can help medical therapy and prevent patients from experiencing malnutrition during the treatment period (Ariana et al., 2011). However, in certain conditions such as swallowing disorders, unconsciousness, and loss of appetite, the patient may experience difficulty in fulfilling their nutritional needs orally so the intake is done through the enteral route as long as the digestive system is still functioning (Pandaleke et al., 2014).

The hyperglycemia enteral formula in Indonesia is generally available in the form of commercial formulas, where the price is relatively more expensive resulting in an increase in hospitalization cost for patients. Over time, many hospitals developed enteral formulas (FERS) but have a relatively shorter shelf life because it is in liquid form. Innovations in the development of hospital enteral formula (FERS) using affordable local food ingredients in powder form becomes indispensable.

Enteral formulas requirements for hyperglycemia patients must have hypoglycemic targets according to ADA, CDA and ASPEN (National Dysphagia Diet Task Force \% American Dietetic Association, 2002; Cheng and Lau, 2013; Mc Mahon et al., 2013; Gosmanov and 
Umpierrez, 2013; American Diabetes Association, 2014; Sanz-Paris et al., 2017). Referring to the requirements, jicama is chosen as one of the ingredients because of its affordable price and its benefit in reducing blood glucose levels in hyperglycemia.

Jicama (Pachyrhizus erosus) contains 14\% inulin which higher than wheat and bananas. Inulin is a soluble fiber that slows gastric emptying so the absorption of the nutrients will slow down and prevent an increase in blood glucose levels. In experimental studies on animals, the use of jicama at a dose of $4 \mathrm{~mL} /$ day can reduce blood glucose levels by $60 \mathrm{mg} / \mathrm{dl}$. However, jicama has $85 \mathrm{~g}$ of water content, causing a relatively short 6 days shelf life if not handled properly. Therefore in this study, jicama is processed into jicama flour to extend shelf life and maintain its nutritional quality (Pangesti et al., 2014).

High protein requirements in hyperglycemia enteral formulas used to prevent protein catabolism. Tempeh, a product derived from soy fermentation (Glycine max) has high arginine amino acids and glycine that can increase insulin secretion and glucagon from the pancreas, as well as isoflavone in the form of the genistein and daidzein genes that inhibit $\alpha$-glucosidase activities which slow the absorption of carbohydrates into glucose (Suarsana, 2010).

For hyperglycemia patients, the type of fat becomes important compared to the amount. Soybean oil contains $50-60 \%$ polyunsaturated fatty acid (PUFA) in the form of linoleic acid which can increase insulin sensitivity and 24\% monounsaturated fatty acid (MUFA) that plays a role in reducing oxidative stress that increases in hyperglycemia patients (Departemen Kesehatan RI, 1995). In addition, soybean oil contains $1328 \mathrm{mg} / \mathrm{kg}$ tocopherol (vitamin E), moreover has the highest $\gamma$ tocopherol $(599.5 \mathrm{mg} / \mathrm{kg})$ among sunflower oil, corn oil, and rapeseed oil (Ergonul and Koseoglu, 2014). $\gamma$ tocopherol has the highest ability in removing free radical $\mathrm{NO}(\mathrm{X})$ among the isomers of vitamin $\mathrm{E}$ (Grilo et al., 2014).

Other ingredients such as skim milk, maltodextrin and sugar are used to complete the formula requirements. Skim milk play roles in making the formula more homogeneous and increase its viscosity (Bienvenue et al., 2004). The use of maltodextrin serves as a source of complex carbohydrates, source of energy, easy to digest, and has a slow absorption so it does not increase blood glucose levels significantly. Granulated sugar used to increase energy, carbohydrates, taste, and improves the flavor of the formulas.

Based on the benefits of tempeh and jicama flour in reducing blood glucose levels and the limited research on enteral formulas with local and affordable food ingredients, researchers are interested in analyzing physical characteristic and nutrition content of homemade powder enteral formula from tempeh and jicama flour with the name of "GLITEROS". This study aimed to measure viscosity, macro-nutrient content, food fiber, and protein digestibility of GLITEROS. GLITEROS enteral formula will be divided into 3 variations that have been adjusted according to the requirements of the enteral diet for hyperglycemia patients according to the American Diabetes Association (ADA), Canadian Diabetes Association (CDA), and the American Society of Parenteral and Enteral Nutrition (ASPEN).

\section{Materials and methods}

\subsection{Study design}

This study included in the field of nutrition and food and was an experimental study using 3 levels of treatments namely variations in the ratio of tempeh flour and jicama flour (A1, A2 and A3) which obtained based on the preliminary studies results that had been previously done. The study was conducted in March May 2019 at CV Chem-Mix Pratama Laboratory Analysis Yogyakarta to test the content of macronutrients, food fiber, protein digestibility, and viscosity.

\subsection{Ingredients of the formula}

The ingredients used in this research were tempeh flour and jicama flour which dried by the oven, "Indoprima" skim milk, "Happy" soybean oil, maltodextrin, and "Gulaku" refined sugar. This research was divided into preliminary research and primary research. Preliminary research was conducted to determine the nutrient contents in tempeh flour and jicama after being dried using the oven.

\subsection{Determination of the formula}

Determining the level of treatment was done by using an estimated calculation of the material used based on its requirement. The requirements for enteral formulas for hyperglycemia patients must have hypoglycemic targets, osmolarity ranging from $300-450 \mathrm{mOsm} / \mathrm{kg}$, and viscosity of $1-50 \mathrm{cP}$ with energy densities of $1-1.2 \mathrm{kcal} /$ $\mathrm{mL}$, energy content ranging from $15-25 \mathrm{kcal} / \mathrm{kg} / \mathrm{day}$, carbohydrates for $45-60 \%$ of total energy, $20-35 \%$ fat with $7-10 \%$ source of monounsaturated fatty acids (MUFA), 15-20\% protein, $14 \mathrm{~g} / \mathrm{L}$ soluble fiber and maximum use of 5\% sugar (National Dysphagia Diet Task Force \% American Dietetic Association, 2002; Cheng and Lau, 2013; Mc Mahon et al., 2013; Gosmanov and Umpierrez, 2013; American Diabetes Association, 2014; Sanz-Paris et al., 2017). 
This study also conducts flow testing with the Viswaldeter Ostwald to determine the variation of the ratio used. Material formulations can be seen in Table 1 . The three GLITEROS enteral formulas had the same 1 $\mathrm{kcal} / \mathrm{mL}$ energy density. The differences in formulas A1, A2 and A3 lied in the comparison of the composition of tempeh flour and jicama flour; the formula A1 (1:1), A2 (5:3) and A3 (2:3).

Table 1. Composition of enteral formula based on tempeh flour and bengkuang flour

\begin{tabular}{lccc}
\hline Composition & Formula A1 & Formula A2 & Formula A3 \\
\hline Tempeh flour (g) & 60 & 70 & 60 \\
Jicama flour (g) & 60 & 42 & 90 \\
Skim Milk (g) & 50 & 50 & 50 \\
Soybean Oil (g) & 15 & 15 & 15 \\
Maltodextrin (g) & 50 & 50 & 50 \\
Granulated sugar (g) & 13 & 13 & 13 \\
Total (g) & 248 & 240 & 278 \\
\hline
\end{tabular}

\subsection{Formula preparation}

Before making enteral formula, the tempeh flour and jicama flour were made using the oven drying method. Thinly sliced tempeh was blanched for 10 mins using hot water to reduce the unpleasant taste and baked at $60^{\circ} \mathrm{C}$ temperature for 6 hours (Mursyid et al., 2014). Dried tempeh then blended and sieved using an 80-mesh sieve. For the jicama flour, it was done by thinly slicing the jicama and blanching it for 1 min using hot water to inhibit the browning reaction. Then, the jicama that has been blanched was roasted with $65^{\circ} \mathrm{C}$ temperature for 7 hours. The dried jicama was then blended and sieved using an 80-mesh sieve to obtain smaller jicama flour particles.

The process of making enteral formulas started by weighing the ingredients according to each comparison. Dry ingredients such as tempeh flour, jicama flour, skim milk, maltodextrin, and refined sugar were mixed manually for 3 mins. Then soybean oil was added to the dry ingredients mixture and stirred for two minutes. All materials that had been stirred manually were stirred again using a mixer for eight minutes so that it became homogeneous.

\subsection{Viscosity test, macro-nutrient content, food fiber, and} protein digestibility

Each comparison of enteral formulas was analyzed by viscosity test, macro-nutrient content, food fiber, and protein digestibility with $3 \mathrm{x}$ repetitions. Viscosity test was done using Brookfield Viscometer. Nutrient content includes protein tested by using the Kjeldahl method, fat content by the Soxhlet method, and carbohydrate content by difference method (Cunniff, 1995). The energy content was obtained by calculating $4 \mathrm{kcal} / \mathrm{g}$ protein +9 $\mathrm{kcal} / \mathrm{g}$ fat $+4 \mathrm{kcal} / \mathrm{g}$ carbohydrate. After the energy content discovered, the energy density obtained by dividing energy content by the volume. Dietary fiber used the multienzyme method (Cunniff, 1995). Protein digestibility used the enzymatic in vitro method with the pepsin enzyme.

\subsection{Statistical analysis}

Carbohydrate content and protein digestibility data were normally distributed analyzed by One-way ANOVA test and followed by Tukey post hoc test. Viscosity data were analyzed by One-way ANOVA test and followed by the Duncan test. The data of energy density, energy and protein content, fat, and food fiber that were not normally distributed were further analyzed by the Kruskal-Wallis test and Mann-Whitney test to find out the real differences between treatments.

\section{Results}

\subsection{Viscosity}

Viscosity is a method used to show the flow of liquid. The viscosity requirements based on $\mathrm{ADA}, \mathrm{CDA}$ and ASPEN are 1-50 cP, but if it based on the Thickened Enteral Formula (TEF), it is $16-20 \mathrm{cP}$. Viscosity in enteral formulas must have met the established standards in order to pass through a catheter or sonde. The results of the viscosity analysis of "GLITEROS" enteral formula can be seen in Table 2 .

Table 2. Viscosity (cP) of enteral formula "GLITEROS"

\begin{tabular}{ccc}
\hline Enteral Formula & Mean \pm SD & $\mathrm{p}$ \\
\hline A1 & $16.40 \pm 2.27^{\mathrm{b}}$ & $0.000^{*}$ \\
A2 & $11.73 \pm 1.02^{\mathrm{b}}$ & \\
A3 & $36.10 \pm 11.33^{\mathrm{a}}$ &
\end{tabular}

Values with different superscript letters show significant difference with the Duncan test.

* Testing with One-way ANOVA

The viscosity of "GLITEROS" enteral formula ranged from 11.73 to $36.10 \mathrm{cp}$. Increasing the proportion of jicama flour tends to increase the viscosity of the enteral formulas. One-way ANOVA statistical analysis results showed that the proportion of tempeh flour and jicama flour gave a significant difference $(p=0.000)$ to the viscosity value of "GLITEROS" enteral formula. Further analysis with Duncan showed that there were significant differences in A3 formula with $\mathrm{A} 1$ and $\mathrm{A} 2$ formulas while A1 formula did not differ significantly from A2 formula. 


\subsection{Macro-nutrient, dietary fiber and protein digestibility}

The results of nutrient content and digestibility analysis of "GLITEROS" enteral formula can be seen in Table 3.

The energy density of "GLITEROS" enteral formula ranges from $0.98-1.13 \mathrm{kcal} / \mathrm{mL}$. A2 formula has the lowest average energy density compared to other formulas. Statistical analysis showed that the proportion of tempeh flour and jicama flour gave a significant difference $(p=0.001)$ to the "GLITEROS" enteral formula energy density. A2 formula has the lowest average energy content compared to A1 and A3 formulas. Statistical analysis showed that there were significant differences $(p=0.001)$ in the three formula samples.

Carbohydrate levels of "GLITEROS" enteral formula ranged from 61.17 to $62.03 \%$. Based on the results of statistical analysis, there were no significant differences in the three enteral formulas $(p=0.258)$. This means that the enteral formula carbohydrate content at each treatment level is relatively the same.

The results of statistical analysis of GLITEROS enteral formula protein levels showed that there were significant differences in $\mathrm{A} 3$ formula with $\mathrm{A} 1$ and $\mathrm{A} 2$ formulas while A1 formula had no significant differences with A2 formula.

The fat content in "GLITEROS" enteral formula ranged from $10.46-11.40 \%$. The results of the KruskalWallis statistical analysis showed that there were no significant differences in the three formulas. This means that the fat content in the three formulas is relatively the same.

Statistical analysis of food fiber content showed that the proportion of tempeh flour and jicama flour gave a significant difference $(p=0.009)$. Further analysis showed that there were significant differences in A1 and A2 formulas while A1 formula did not differ significantly from A2 and A3 formulas.

The protein digestibility of "GLITEROS" enteral formula ranges from $52-59 \%$. Statistical analysis showed that there were significant differences in A3 formula with $\mathrm{A} 1$ and $\mathrm{A} 2$ formulas, while A1 formula did not differ significantly from A2 formula.

\section{Discussion}

Viscosity is an important characteristic of enteral food to pass through a catheter or sonde. Viscosity in liquid food can experience changes due to temperature, fat and protein content, solution concentration, and solidto-liquid fat ratio (Bienvenue et al., 2004)

The "GLITEROS" enteral formula has a viscosity value ranging from 11.30-36.10 cP. The standard viscosity of enteral formulas based on the American Dietetic Association is 1-50 cP, where all three enteral formulas are eligible (National Dysphagia Diet Task Force and American Dietetic Association, 2002). However, if compared to the viscosity of the Thickened Enteral Formula (TEF), thickened enteral formula reduce complications such as diarrhea and hyperglycemia by 16 $-20 \mathrm{cP}, \mathrm{A} 3$ formula does not meet the requirements (Wakita et al., 2015).

Jicama flour proportion addition tends to increase the viscosity of the GLITEROS enteral formula. A3 formula has the highest viscosity value compared to $\mathrm{A} 1$ and $\mathrm{A} 2$ formulas with the of $90 \mathrm{~g} / 1000 \mathrm{~mL}$ jicama flour proportion. Jicama flour has a high starch content which is $73.47 \%$; the higher the starch content, the higher the ability to absorb water. During the process of brewing the formula with hot water, starch granules begin to swell and the process of water absorption occurs. The absorbed water is locked in starch granules and cannot

Table 3. Macro nutrient, dietary fiber and protein digestibility of enteral formula "GLITEROS"

\begin{tabular}{lcccc}
\hline \multirow{2}{*}{ Nutriet content/1000 mL } & \multicolumn{4}{c}{ Enteral Formula } \\
\cline { 2 - 5 } & $\mathrm{A} 1$ & $\mathrm{~A} 2$ & $\mathrm{~A} 3$ & $\mathrm{p}$ \\
\hline Energy Density (kcal/mL) & $1.01 \pm 0.15$ & $0.98 \pm 0.16$ & $1.13 \pm 0.01$ & $0.001^{* *}$ \\
Energy (kcal) & $1010.20 \pm 14.57$ & $983.98 \pm 15.98$ & $1132.45 \pm 8.98$ & $0.001^{* *}$ \\
Carbohydrate (\%) & $62.03 \pm 1.12$ & $61.20 \pm 1.18$ & $61.17 \pm 0.44$ & $0.258^{*}$ \\
Protein (\%) & $16.28 \pm 0.36$ & $16.35 \pm 0.23$ & $14.89 \pm 0.31$ & $0.003^{* *}$ \\
Fat (\%) & $10.46 \pm 1.27$ & $11.08 \pm 1.14$ & $11.40 \pm 0.60$ & $0.299^{* *}$ \\
Dietary fiber (\%) & $25.59 \pm 1.49$ & $18.64 \pm 4.26$ & $20.26 \pm 3.68$ & $0.009^{* *}$ \\
Protein digestibility (\%) & $52.00 \pm 2.21^{\mathrm{b}}$ & $52.74 \pm 2.81^{\mathrm{b}}$ & $59.00 \pm 4.62^{\mathrm{a}}$ & $0.005^{*}$ \\
Water (\%) & $9.00 \pm 0.27^{\mathrm{b}}$ & $8.99 \pm 0,44^{\mathrm{b}}$ & $10.18 \pm 0.39^{\mathrm{a}}$ & $0.000^{*}$ \\
Ash (\%) & $2.23 \pm 0.13$ & $2.36 \pm 0.30$ & $2.31 \pm 0.31$ & $0.683^{*}$ \\
\hline
\end{tabular}

Values with different superscript letters show significant difference with the Duncan test.

* Testing with One-way ANOVA, ** Testing with Kruskal-Wallis. 
come out bonding to form a gel, thus increasing the viscosity.

In addition, another factor affects the increase in viscosity of GLITEROS enteral formula is the solution concentration. High concentrated solution will also have a high viscosity. The concentration of the solution stated the number of particles that dissolved per unit volume. The more particles dissolved, the higher the friction between the particles so that the viscosity increases (Sinila, 2016). A3 Formula has $278 \mathrm{~g} / 1000 \mathrm{~mL}$ solids so it has the highest viscosity while A2 has only $240 \mathrm{~g} / 1000$ $\mathrm{mL}$ solids, so it has the lowest viscosity compared to other formulas.

The energy content of the three "GLITEROS" enteral formulas ranges between 983.98-1132.45 kcal/ $\mathrm{mL}$, so the resulting energy density ranges from 0.98 $1.13 \mathrm{kcal} / \mathrm{mL}$. The energy density of $\mathrm{A} 1$ and $\mathrm{A} 3$ formulas are in accordance with the requirements of the enteral formula which is $1-1.2 \mathrm{kcal} / \mathrm{mL}$. Meanwhile, A2 formula has not met the requirements. This is due to the number of solids in the A2 formula being less than the $\mathrm{A} 1$ and $\mathrm{A} 3$ formulas which were $240 \mathrm{~g} / 1000 \mathrm{~mL}$. The amount of solid increases the viscosity of the formula, while the formula viscosity is directly proportional to the energy content and energy density. The higher the viscosity of formula, the higher the energy content and energy density.

Carbohydrates are the main source of energy for human metabolism. The amount of energy that can be produced by 1 gram of carbohydrate is $4 \mathrm{kcal}$ (Gropper et al., 2009). The percentage of carbohydrates of the three GLITEROS enteral formulas ranges from 61.17 to $62.03 \%$, in which the carbohydrate content of the three formulas has exceeded the requirements of $45-60 \%$. In $100 \mathrm{~g}$ of maltodextrin contains $95.21 \mathrm{~g}$ of carbohydrate (Fatsecret, 2020). Furthermore, based on the nutrition fact written in the package, sugar contains $94 \mathrm{~g}$ of carbohydrate over $100 \mathrm{~g}$ of product. A preliminary study revealed that in $100 \mathrm{~g}$ of raw materials, jicama flour has $59.3 \mathrm{~g}$ of carbohydrate while tempeh flour has $23 \mathrm{~g}$. Among these ingredients, sugar is the one which contains simple carbohydrate.

Simple carbohydrate intake such as monosaccharides and disaccharides can increase blood glucose levels and worsen hyperglycemia conditions experienced by patients. But, in this study, the high levels carbohydrates used for the enteral formula are the type of complex carbohydrates (polysaccharides), so they do not potentially increase blood glucose levels significantly (Gropper et al., 2009).

A3 formula has the lowest carbohydrate content compared to A1 and A2 formulas. This is due to the GLITEROS enteral formula carbohydrate content being calculated using the by difference method where the results of the calculation are influenced by water, ash, protein and fat content (Bender, 2020). A3 formula has a high proportion of jicama flour which is $90 \mathrm{~g} / 1000 \mathrm{~mL}$, but the water content in A3 formula is also high, 10.18\%, thus reducing the carbohydrate content.

The higher the proportion of tempeh flour, the higher the protein level contained in GLITEROS enteral formula. This is because the tempeh flour protein content is higher compared to jicama flour which is $46 \%$. The percentage of protein in the formula ranged from 14.89 to $16.35 \%$ of total calories. A1 and A2 formulas meet the requirements of the enteral formula for hyperglycemia which is $15-20 \%$, while the A3 formula did not meet the requirements. The high levels of protein in hyperglycemic conditions used for the formation of damaged tissue and help cell growth (Istiqomah and Rustanti, 2015). Tempeh contains a lot of arginine amino acids and glycine which can increase insulin secretion and glucagon from pancreas. Tempeh also contains flavonoids in the form of genistein and daidzein which inhibit the $\alpha$-glucosidase activity so it slows the absorption of carbohydrates into glucose and suppresses the rise of blood glucose level (Bintari et al., 2015)

The GLITEROS enteral formula fat source comes from soybean oil and tempeh flour. Soybean oil is a vegetable oil containing polyunsaturated fatty acids (PUFA) in the form of linoleic acid as much as $50-60 \%$. Linoleic acid helps increase insulin sensitivity and reduces the inflammatory response in hyperglycemic conditions. In addition to PUFA content, soybean oil also has $24 \%$ monounsaturated fatty acid (MUFA) which is useful in repairing serum glucose, blood pressure and reducing oxidative stress (List, 2015). Tempeh flour also contains $7.23 \mathrm{~g}$ of linoleic acid. The percentage of fat in "GLITEROS" enteral formula ranges between 10.46$11.40 \%$ where the three formulas do not meet the requirements of the enteral hyperglycemia formula according to ASPEN which is $20-35 \%$ of the total energy. This is because, during the formulation process of enteral ingredients, soybean oil is much sticking to the container used for weighing and mixing the ingredients, causing the composition of soybean oil to not match the quantities made. Therefore, it is recommended to minimize the use of containers by using only one to reduce the risk of the lack of oil weight.

Food fiber is a part of food that cannot be hydrolyzed by digestive enzymes. Based on the solubility, food fiber is divided into two namely soluble and insoluble. The percentage of dietary fiber content in 
GLITEROS enteral formula ranged from 18.64-25.59\% where the three formulas had exceeded the requirements which was $14 \mathrm{~g} / \mathrm{L}$. The high fiber content of the GLITEROS enteral formula is due to the high level of jicama flour which is $17.72 \%$ (Paramita and Putri, 2015). The presence or absence of fiber content in enteral formulas is still contraindicated. Fiber can help control blood glucose levels. Fiber is able to absorb water and bind glucose, thereby reducing glucose availability. In the small intestines, fiber increases the viscosity of intestinal contents which results in a decrease of the $\alpha$ amylase enzyme and slows glucose absorption, thus reducing the rise in blood glucose (Wulandari and Wirawanni, 2014). However, the excess fiber content in enteral formulas can inhibit the absorption of other nutrients such as vitamins and minerals. The fiber ability to absorb water that is high enough caused the other nutrients to be bound together with it and subsequently excreted through feces (Reis et al., 2018).

Protein digestibility is the proteins ability to be hydrolyzed into amino acids by digestive enzymes. The higher the digestibility of the protein, the higher the protein can be hydrolyzed into amino acids that are absorbed and used by the body (Saputra, 2014). Protein digestibility can be influenced by several factors namely the presence of anti-nutrient compounds (phytic acid, protease inhibitors, and hemagglutinin), the processing (Maillard reaction and denaturation of proteins), and the reaction of protein with other compounds (polyphenols, fats, carbohydrates and fiber).

The protein digestibility of GLITEROS enteral formula ranges from $52-59 \%$. The decreased of protein digestibility along with carbohydrates increased levels because carbohydrates bind to protein molecules and inhibit the process of protein hydrolysis into amino acids. In addition, decreased protein digestibility is also caused by the presence of food fiber. When food fibers bind to proteins, protease enzymes will find it difficult to penetrate and break their peptide bonds, preventing proteins from being digested properly and causing the absorption of amino acids to be inefficient (Kim et al., 2013)

GLITEROS enteral formula that has approached nutrient requirements according to the American Diabetes Association (ADA), Canadian Diabetes Association (CDA), and the American Society of Parenteral and Enteral Nutrition (ASPEN) is A1 formula with a ratio 1:1 of tempeh flour and jicama flour. A1 formula was chosen because it has viscosity, energy density, energy and protein content that are in accordance with formula requirements. However, the levels of carbohydrates, fats, and dietary fiber do not meet the requirements.

\section{Conclusion}

The comparison of tempeh flour and jicama flour gives significant differences to the value of viscosity, energy density, energy and protein content, food fiber and protein digestibility. A1 formula is the best compared to other formulas because of the value of viscosity, energy density, energy and protein content that meets the requirements of hyperglycemia enteral formula according to ADA, CDA and ASPEN.

\section{Conflict of interest}

The authors declare there is no conflict of interests related to the publication of this paper.

\section{Acknowledgments}

The GLITEROS enteral formula research was fully funded by Diponegoro University state budget fiscal year 2018 through Research Development and Application program. The author would like to thank all those who have helped this research to be done properly.

\section{References}

American Diabetes Association. (2014). Standards of medical care in diabetes - 2014. Diabetes Care, 37 (Suppl. 1), S14-S80. https://doi.org/10.2337/dc14S014

Ariana, R., Pichardo, L., Chris, Y.F. and Robert, A.G. (2011). Management of hyperglycemia in the nonintensive care patient: featuring subcutaneous insulin protocols. Endocrine Practice, 17(2), 249-260. https://doi.org/10.4158/EP10220.RA

Bienvenue, A., Jimenez-Flores, R. and Singh, H. (2003). Rheological properties of concentrated skim milk: Importance of soluble minerals in the changes in viscosity during storage. Journal of Agricultural and Food Chemistry, 51(22), 6488-6494. https:// doi.org/10.1021/jf034050+

Bintari, S.H., Putriningtyas, N.D., Nugraheni, K., Widyastiti, N.S., Dharmana, E. and Johan, A. (2015) Comparative effect of tempe and soymilk on fasting blood glucose, insulin level, and pancreatic beta cell expression (study on streptozotocin-induced diabetic rats). Pakistan Journal of Nutrition, 14(4), 239-246. https://doi.org/10.3923/pjn.2015.239.246

Cheng, A.Y.Y. and Lau, D.C.W. (2013). The Canadian Diabetes Association 2013 Clinical Practice Guidelines - Raising the Bar and Setting Higher Standards!. Canadian Journal of Diabetes, 37(3), 137-138. https://doi.org/10.1016/j.jcjd.2013.04.005

Cunniff, P. (1995). Official Methods of Analysis of AOAC International. Washington D.C., USA: 
Association of Official Analytical Chemists.

Departemen Kesehatan RI. (1995). Daftar Komposisi Zat Gizi Pangan Indonesia Edisi 1995. Jakarta: Direktorat Jendral Pembinaan Kesehatan Masyarakat. [In Bahasa Indonesia].

Ergonul, P.G. and Koseoglu, O. (2014). Changes in $\alpha-, \beta$ ,$- \gamma-, \delta$-tocopherol contents of mostly consumed vegetable oils during refining process. CyTA-Journal of Food, 12(2), 199-202. https:// doi.org/10.1080/19476337.2013.821672

Fatsecret. (2020). Maltodextrin. Retrieved on March 1, 2020 from fatsecret Website : https:// www.fatsecret.com/calories-nutrition/generic/ maltodextrin

Godinjak, A., Iglica, A., Burekovic, A., Jusufovic, S., Ajanovic, A., Tancica, I. and Kukuljac, A. (2015). Hyperglycemia in critically ill patients: management and prognosis. Medical Archives, 69(3), 157-160. https://doi.org/10.5455/medarh.2015.69.157-160

Grilo, E.C., Costa, P.N., Gurgel, C.S.S., Beserra, A.F.L., Almeida, F.N.S. and Dimenstein, R. (2014). Alphatocopherol and gamma-tocopherol concentration in vegetable oils. Food Science and Technology, 34(2), 379-385. https://doi.org/10.1590/S010120612014005000031

Gropper, S.S., Smith, J.L. and Groff, J.L. (2009). Advanced nutrition and human metabolism. 5th ed., p. 63-99. USA: Wadsworth Cengage Learning.

Gosmanov, A.R. and Umpierrez, G.E. (2013). Management of hyperglycemia during enteral and parenteral nutrition therapy. National Institute of Health Public Access, 13(1), 155-162. https:// doi.org/10.1007/s11892-012-0335-y

Istiqomah, A. and Rustanti, N. (2015). Glycemic Index, glycemic load, protein content, fiber and the preference level of arrowroot flour pastries with red bean flour substitution. Journal of Nutrition College, 4(2), 620-627.

Kim, S.-L., Lee, J.-E., Kwon, Y.-U., Kim, W.-H., Jung, G.-H., Kim, D.-W., Lee, C.-K., Lee, Y.-Y., Kim, M.J., Kim, Y.-H., Hwang, T.-Y. and Chung, I.-M. (2013). Introduction and Nutritional Evaluation of Germinated Soygerm. Food Chemistry, 136(2), 491500. https://doi.org/10.1016/j.foodchem.2012.08.022

List, G.R. (2015). Oilseed composition and modification for health and nutrition. In Sanders, T. (Ed.). Functional Dietary Lipid., p. 23-46. UK: Woodhead Publishing. https://doi.org/10.1016/B978-1-78242247-1.00002-8

Mc Mahon, M.M., Nystrom, E., Braunschweig, C., Miles, J. and Compher, C. (2013). ASPEN Board of Director. Aspen clinical guidelines: nutrition support of adult patients with hyperglycemia. Journal of Parenteral and Enteral Nutrition, 37(1), 23-36. https://doi.org/10.1177/0148607112452001

Mursyid., Astawan, M., Muchtadi, D., Wresdiyati, T., Widowati, S., Bintari, S.H. and Suwarno, M. (2014). Evaluate the nutrition value of tempeh flour protein made from import and local soybean varieties. Food Journal, 23(1), 33-41.

National Dysphagia Diet Task Force, American Dietetic Association. (2002). National dysphagia diet: standardization for optimal care. Chicago: American Dietetic Association.

Bender, D.A. (Ed.). (2020). Overview: Carbohydrate by difference. In A Dictionary of Food and Nutrition. $3^{\text {rd }}$ ed. United Kingdom: Oxford University Press.

Pandaleke, J.J.C., Sengkey, L.S. and Angliadi, E. (2014). Medical rehabilitation in patients with dysphagia. Biomedic Journal, 6(3), 157-164. https:// doi.org/10.35790/jbm.6.3.2014.6321

Pangesti, Y.D., Parnanto, N.H.R. and Ridwan, A. (2014). The study on physicochemical characteristics yam bean flour (Pachyrhizus erosus) modified by heat moisture treatment (HMT) temperature variation. Jurnal Teknosains Pangan, 3(3), 72-77.

Paramita, A.H. and Putri, W.D.R. (2015). Effect of addition yam flour and steaming duration on physico -chemical and sensory qualities of taro flakes. Jurnal Pangan dan Agroindustri, 3(3), 1071-1082.

Sanz-Paris, A., Hernandez, J.A., Ballesteros-Pomar, M.D., Botella-Romero, F., Leon-Sanz, M., MartinPalmero, A., Olmos, M.A.M. and Olveira, G. (2017). Evidence-based recommendations and expert consensus on enteral nutrition in the adult patient with diabetes mellitus or hyperglycemia. Nutrition, 41, 58-67. https://doi.org/10.1016/j.nut.2017.02.014

Reis, A.M.D., Fruchtenicht, A.V., Loss, S.H. and Moreira, L.F. (2018). Use of dietary fibers in enteral nutrition of critically ill patients: a systematic review. Revista Brasileira de Terapia Intensiva, 30 (3), 358-365. https://doi.org/10.5935/0103$507 X .20180050$

Saputra, D. (2014). Determination of in vitro protein digestibility of pomfret (Colossoma macropomum) at different harvest ages. ComTech, 5(2), 1127-1133.

Sinila, S. (2016). Farmasi Fisik, p. 62-63. Jakarta Selatan: Kementrian Kesehatan Republik Indonesia. [In Bahasa Indonesia].

Suarsana, I.N. (2010). Analysis of isoflavones activity of tempeh against $\alpha$-glucosidase inhibition and its effect on hyperglycemic mice. Jurnal Ilmu Kefarmasian Indonesia, 8(10), 74-79. [In Bahasa Indonesia].

Wakita, M., Masui, H., Ichimaru, S. and Amagai, T. 
(2015). Determinant Factors of the Viscosity of Enteral Formulas: Basic Analysis of Thickened Enteral Formulas. Nutrition in Clinical Practice, 27
(1),
82-90.
https://

doi.org/10.1177/0884533611427146

Wulandari, N.E. and Wirawanni, Y. (2014). The effect of broccoli administration on fasting blood glucose levels in prediabetic women. Journal of Nutrition College, 3(4), 547-553. 